\title{
Thyroid Hormone Receptors in Two Model Species for Vertebrate Embryonic Development: Chicken and Zebrafish
}

\author{
Veerle M. Darras, ${ }^{1}$ Stijn L. J. Van Herck, ${ }^{1}$ Marjolein Heijlen, ${ }^{1}$ and Bert De Groef ${ }^{1,2}$ \\ ${ }^{1}$ Division Animal Physiology and Neurobiology, Biology Department, Laboratory of Comparative Endocrinology, K.U.Leuven, \\ 3000 Leuven, Belgium \\ ${ }^{2}$ Department of Agricultural Sciences, Centre for Agribiosciences, La Trobe University, Bundoora, VIC 3086, Australia
}

Correspondence should be addressed to Veerle M. Darras, veerle.darras@bio.kuleuven.be

Received 24 February 2011; Accepted 1 April 2011

Academic Editor: Michelina Plateroti

Copyright (c) 2011 Veerle M. Darras et al. This is an open access article distributed under the Creative Commons Attribution License, which permits unrestricted use, distribution, and reproduction in any medium, provided the original work is properly cited.

Chicken and zebrafish are two model species regularly used to study the role of thyroid hormones in vertebrate development. Similar to mammals, chickens have one thyroid hormone receptor $\alpha(\operatorname{TR} \alpha)$ and one TR $\beta$ gene, giving rise to three TR isoforms: $\operatorname{TR} \alpha, \operatorname{TR} \beta 2$, and $\operatorname{TR} \beta 0$, the latter with a very short amino-terminal domain. Zebrafish also have one TR $\beta$ gene, providing two $\mathrm{TR} \beta 1$ variants. The zebrafish TR $\alpha$ gene has been duplicated, and at least three TR $\alpha$ isoforms are expressed: TR $\alpha \mathrm{A} 1-2$ and TR $\alpha \mathrm{B}$ are very similar, while TR $\alpha \mathrm{A} 1$ has a longer carboxy-terminal ligand-binding domain. All these TR isoforms appear to be functional, ligand-binding receptors. As in other vertebrates, the different chicken and zebrafish TR isoforms have a divergent spatiotemporal expression pattern, suggesting that they also have distinct functions. Several isoforms are expressed from the very first stages of embryonic development and early chicken and zebrafish embryos respond to thyroid hormone treatment with changes in gene expression. Future studies in knockdown and mutant animals should allow us to link the different TR isoforms to specific processes in embryonic development.

\section{Introduction}

Thyroid hormones (THs) play an important role in development by controlling the growth and differentiation of almost every organ in the vertebrate body. They act mainly, although not exclusively, by binding to intracellular TH receptors (TRs), members of the nuclear receptor superfamily. TRs are ligand-inducible transcription factors that bind 3,5,3'-triiodothyronine $\left(\mathrm{T}_{3}\right)$ or with a lower affinity also $3,5,3^{\prime}, 5^{\prime}$-tetraiodothyronine or thyroxine $\left(\mathrm{T}_{4}\right)$. They function as homodimers or preferentially as heterodimers with other members of the same receptor family, notably the retinoid X receptors (RXRs). TRs recognize specific DNA sequences in the promoter region of TH-responsive genes and can bind to these TH response elements (TREs) even in the absence of ligand. Generally, unliganded TRs are bound to a set of corepressors leading to active repression of gene transcription. Ligand binding induces a conformational change, resulting in release of the corepressors and recruitment of coactivators and stimulation of gene transcription. The molecular mechanisms involved in TR-mediated gene transcription have recently been reviewed in more detail by other authors (e.g., [1-4]).

The first clear evidence for the need of THs in vertebrate development came from frogs, where THs control the transition from an aquatic larva to a terrestrial juvenile during metamorphosis. Since that time, THs have been shown to be involved not only in postnatal/posthatch development but also in earlier stages, both in mammals and in nonmammalian species. All vertebrate embryos have access to THs long before the embryonic thyroid gland starts hormone secretion, either by transplacental transfer in mammals [5] or by TH deposition in the yolk in other vertebrates $[6,7]$. Whether or not these THs can influence early development largely depends on the presence and tissuespecific distribution of TRs in the species investigated. In 
this paper we try to summarize the information available for two nonmammalian model species for vertebrate embryonic development. The chicken is a long-established model for the study of early development. It has been a major model in embryology for more than a century and has recently become even more powerful thanks to the possibilities of gain- and loss-of-function technologies [8]. The zebrafish emerged more recently but became a mainstream model organism for the molecular aspects of development very rapidly, because it combines an external development and a relatively short generation time with several possibilities of genetic manipulation [9].

\section{Different Isoforms of Nuclear TH Receptors}

Vertebrates generally have two TR genes located on different chromosomes, encoding, respectively, thyroid hormone receptor alpha $(\mathrm{TR} \alpha)$ and thyroid hormone receptor beta $(\mathrm{TR} \beta)$. Due to ancestral gene duplication, some nonmammalian vertebrate species, including several fish, have two TR $\alpha$-encoding genes [10]. Each TR consists of an aminoterminal regulatory domain, a central DNA-binding domain, and a carboxy-terminal hormone-binding domain. The latter not only binds THs, but is also involved in the interaction with corepressors and coactivators, and in the dimerisation of the receptors. The structure and function of TRs has been very well conserved throughout vertebrate evolution. They seem to originate from a single TR gene that has a common ancestry with a TR gene found in the cephalochordate Amphioxus and the sea squirt Ciona, and interestingly even in the trematode Schistosoma. This suggests that the origin of the TR gene goes back early in animal evolution $[11,12]$. Each vertebrate TR gene typically gives rise to several variants through alternative splicing and the use of different transcription start sites. In rodents, this leads to three hormone-binding $\operatorname{TR} \beta$ variants $(\operatorname{TR} \beta 1, \operatorname{TR} \beta 2$, and $\mathrm{TR} \beta 3$ ) differing in their amino-terminal domain, one hormone-binding $\mathrm{TR} \alpha$ variant (TR $\alpha 1)$ and two TR $\alpha$ variants ( TR $\alpha 2$ and $\mathrm{TR} \alpha 3$ ) that have a different carboxy-terminus and are not capable of hormone binding. In addition, some truncated TRs have been identified ( $\operatorname{TR} \Delta \beta 3$, TR $\Delta \alpha 1$, and TR $\Delta \alpha 2$ ) that have the capacity to bind THs but that cannot bind to TREs [1]. So far the number of TR isoforms identified in chicken and zebrafish is more restricted, but a more thorough investigation may considerably increase their number as happened in rodents over the last decades.

The presence of nuclear binding sites for $\mathrm{T}_{3}$ was first shown in rat in the early seventies $[13,14]$. Approximately ten years later, similar studies in chicken embryos showed that such binding sites were already present early in embryonic development, in liver, brain, and lung tissue [15-17]. In addition, these studies showed that shifts occurred in the $K_{a}$ values for $\mathrm{T}_{3}$ binding during development and that while nuclei purified from brain of 9-day-old embryos (E9) bound $\mathrm{T}_{3}$ twice as good as $\mathrm{T}_{4}$, this shifted to a 5 -fold better binding of $\mathrm{T}_{3}$ at E17 [16]. This led to the suggestion that maybe more than one type of binding site was present and that their relative abundance might change during development.
The first step to the identification of the molecular structure of TRs was made when it was shown in chicken and in rat that the cellular counterpart of the $v$-erb- $A$ gene coded for a protein capable of binding $\mathrm{T}_{3}$ with the same affinity as the previously identified nuclear binding sites $[18,19]$. As a result, it became clear that the previously described chicken $c$-erb-A gene [20] was the gene for chicken $\mathrm{TR} \alpha$ [18]. A few years later, a cDNA encoding a chicken $\operatorname{TR} \beta$ was characterised. This $\operatorname{cTR} \beta$ closely resembled the human and rat $\operatorname{TR} \beta$ sequences identified at that time, but it had a much shorter amino-terminal domain [21, 22]. Shortly thereafter another $\operatorname{TR} \beta$ with a longer aminoterminal domain was identified [23]. It closely resembled rat $\mathrm{TR} \beta 2$ and was therefore named cTR $\beta 2$, while the previously identified shorter $\operatorname{TR} \beta$ was named $\operatorname{TR} \beta 0$ [23]. It was shown that $\operatorname{TR} \beta 2$ was more efficient in transactivation of a reporter gene than TR $\beta 0[23,24]$. All three chicken TR isoforms have a functional hormone-binding domain and bind $\mathrm{T}_{3}$ with higher affinity than $\mathrm{T}_{4}$. No truncated or non-ligand-binding variants have been described so far. A comparison of the structure of the chicken and mouse TR variants is given in Figure 1.

Two TR genes were originally identified in zebrafish, $\operatorname{TR} \alpha$ and $\operatorname{TR} \beta$, giving rise to the transcripts $\operatorname{TR} \alpha 1$ and $\operatorname{TR} \beta 1$ $[26,27]$. Zebrafish TR $\alpha 1$ showed a high similarity with TR $\alpha$ s from other vertebrates, but it had 14 additional carboxyterminal amino acids that were not found in any other known TR $[26,28]$. Zebrafish TR $\beta 1$ had the typical structure of all other TR $\beta$ s including the short amino-terminal domain $[27,29]$. One year later, a second TR $\beta$ isoform was described that had a 9 -amino acid insert in the hinge region between the DNA- and the ligand-binding domain [28], a feature found in several teleost TR $\beta$ s but not in other vertebrate classes [30]. Comparison of the activity of the $\operatorname{TR} \alpha$ and $\operatorname{TR} \beta$ proteins suggested that $\mathrm{TR} \beta 1$ transactivating activity was ligand-dependent and repressed in the absence of $\mathrm{T}_{3}$, while $\mathrm{TR} \alpha$ had constitutive transactivating activity in the absence of ligand $[27,31]$.

Only recently it was shown that due to ancestral gene duplication, zebrafish has two TR $\alpha$ genes and that they are both expressed $[10,32]$. The originally identified $\operatorname{TR} \alpha$ gene has therefore been renamed thraa, while the second one is called thrab. The thraa gene gives rise to at least two proteins: TR $\alpha \mathrm{A} 1$ and $\mathrm{TR} \alpha \mathrm{A} 1-2$. TR $\alpha \mathrm{A} 1$ corresponds to the original TR $\alpha 1$ with the carboxy-terminal extension while TR $\alpha$ A1-2 does not have this extension [32]. The so-called $\mathrm{F}$ domain extension does not alter the overall structure of $\mathrm{TR} \alpha \mathrm{A} 1$, but it reduces the transcriptional activity of the receptor by changing its affinity for the zebrafish coactivator NCoA2 [32]. The sequence of the ligand-binding domain of $\mathrm{TR} \alpha \mathrm{B}$, the transcript encoded by the thrab gene, is very similar to the one of TR $\alpha \mathrm{A} 1-2$, but based on the predicted sequence, it probably has a shorter amino-terminal domain and some splice variations that might have functional consequences [32]. All the zebrafish TRs mentioned above have a functional hormone-binding domain. However, there is some evidence for the presence of a TR $\beta 2$-like transcript that could encode a truncated TR with a complete DNAbinding domain but no ligand-binding domain [33]. A 


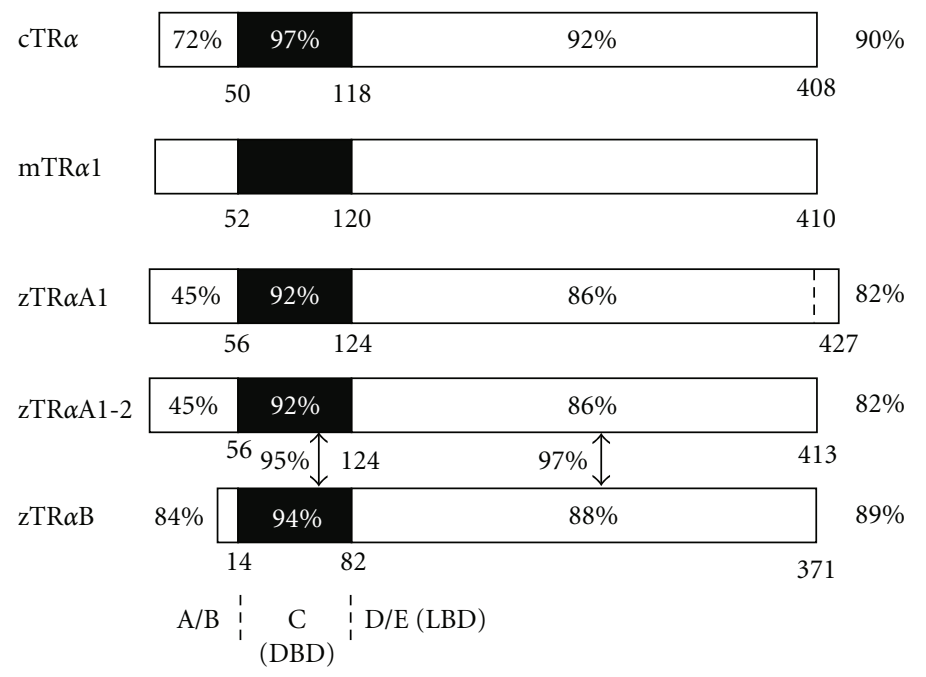

(a)

\begin{tabular}{|c|c|c|c|}
\hline \multirow[t]{2}{*}{ cTR $\beta 0$} & $95 \%$ & \multicolumn{2}{|l|}{$96 \%$} \\
\hline & $2100 \% \uparrow$ & $100 \% \uparrow$ & 69 \\
\hline cTR $\beta 2$ & $95 \%$ & $96 \%$ & $77 \%$ \\
\hline
\end{tabular}
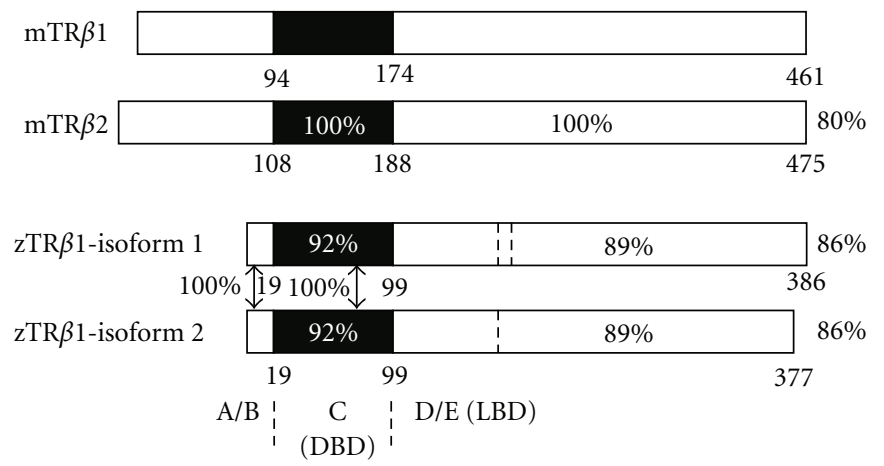

(b)

Figure 1: Comparison of mouse (m), chicken (c), and zebrafish (z) TR isoforms. (a) TR $\alpha$ variants and (b) TR $\beta$ variants. Truncated TR isoforms that do not bind $\mathrm{T}_{3}$ are not included, nor are the TR $\beta 3$ variants that have only been found in rats. Numbering of amino acids is represented under each bar. Percentages within the bars are identities of that domain with the homologous domain of mTR $\alpha 1$ or $\mathrm{mTR} \beta 1$, respectively. Percentages right of the bars give the overall similarity of the entire protein with the canonical mouse homolog. Percentages in between bars show the similarity between the respective domains. A/B: A and B domain; C (DBD): C domain or DNA-binding domain; $\mathrm{D} / \mathrm{E}$ (LBD): $\mathrm{D}$ and $\mathrm{E}$ domain or ligand-binding domain. The dotted line in the D/E domain of $\mathrm{zTR} \alpha \mathrm{A} 1$ marks the first of the 14 additional carboxy-terminal amino acids not found in the other TRs. The dotted lines in the D/E domain of zTR $\beta 1$ isoform 1 delineate a 9-amino-acid insert that is missing in the equivalent location in zTR $\beta 1$ isoform 2 (also indicated with a dotted line). Comparisons were based on the following UniProtKB sequences: mTR $\alpha 1$ (P63058-2), mTR $\beta 1$ (P37242-1), mTR $\beta 2$ (P37242-2), cTR $\alpha 1$ (P04625), cTR $\beta 0$ (P68306), cTR $\beta 2$ (Q91003), zTR $\alpha$ A1 (Q98867-1), zTR $\alpha 1$-2 (Q98867-2), zTR $\alpha$ B (A0ST48), zTR $\beta 1$-isoform 1 (Q9PVE4-1), and zTR $\beta 1$-isoform 2 (Q9PVE4-2).

comparison of the structure of the zebrafish and mouse TR variants is given in Figure 1.

\section{Expression and Distribution of TRs during Embryonic Development}

The expression pattern of chicken and zebrafish TRs has so far been studied predominantly, if not exclusively, at the mRNA level using techniques like Northern blot analysis, in situ hybridisation (ISH), and quantitative reverse transcription polymerase chain reaction (qRT-PCR). While ISH is the only technique providing information on the cell-specific distribution pattern, qRT-PCR is by far the most sensitive one. This difference in detection limit has to be taken into account when comparing the results from different groups published over the years.

Chicken embryonic development takes three weeks from the beginning of incubation to hatching. Studies in early chick embryos have shown that $\operatorname{TR} \alpha$ is expressed earlier 


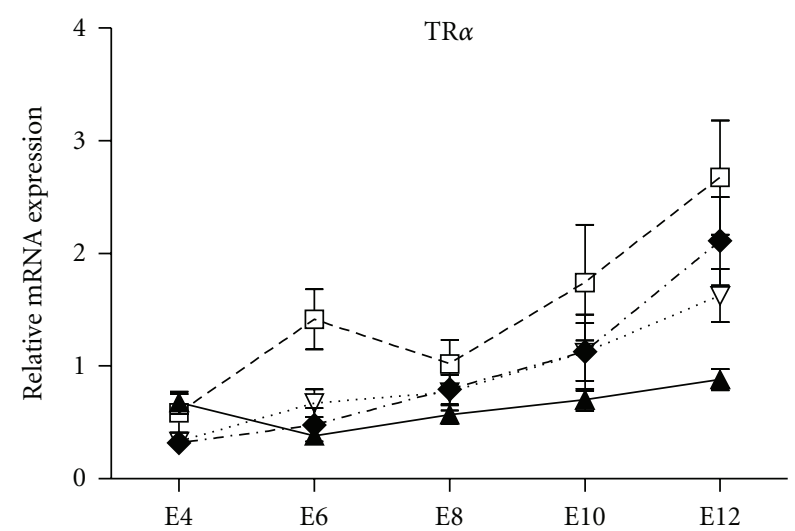

(a)

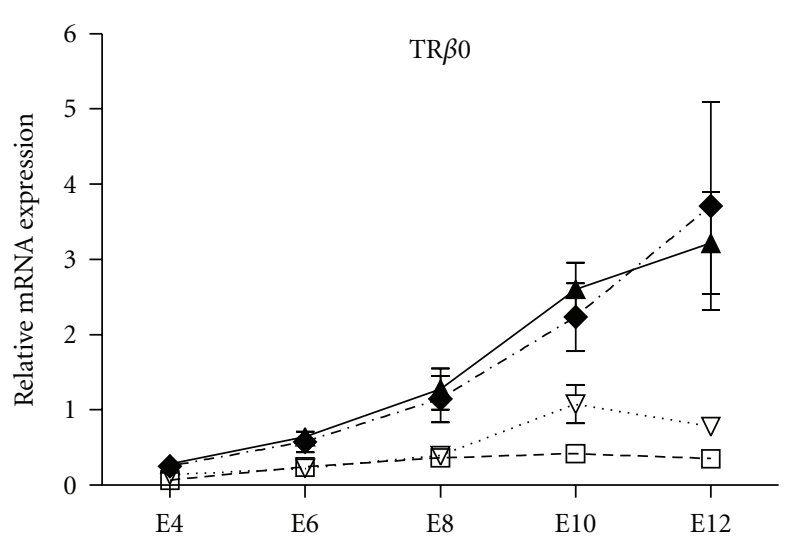

(b)

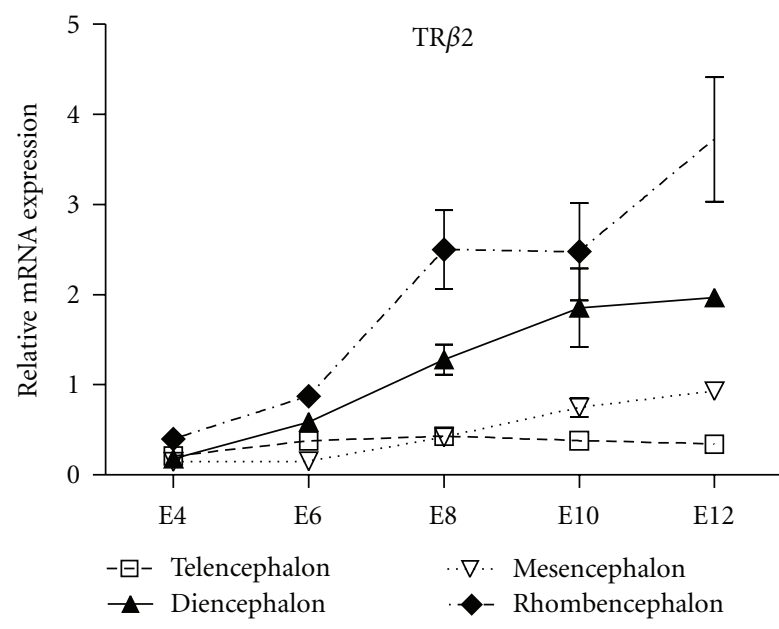

(c)

FIgURE 2: Ontogenetic pattern of $\operatorname{TR} \alpha$, TR $\beta 0$, and TR $\beta 2$ expression in different brain regions of 4- to 12-day-old chick embryos. Specific mRNA levels were measured by qRT-PCR and normalised against a combination of four housekeeping genes: $\beta$ actin, GAPDH, $\beta 2$ microglobulin, and cyclophilin A. Values represent the mean \pm SEM for 6 independent samples per stage.

than TR $\beta$. TR $\alpha$ mRNA was already detected on the first day of incubation and whole-mount ISH in embryos after 18 to 33 hours of incubation showed the highest expression in the neurectoderm [34]. At that time, TR $\beta$ expression was found to be extremely low [34]. This predominance of TR $\alpha$ at early stages was confirmed by Northern blot analysis showing the presence of TR $\alpha$ mRNA in brain, red blood cells and yolk sac at E4, while TR $\beta 0$ mRNA could only be detected from E7 onwards in yolk sac $[21,35]$. Using an RNase protection assay, TR $\beta 2$ mRNA was first detected at E6, specifically in the retina [23]. Recently, qRTPCR analysis by our own group demonstrated that all three known chicken TR variants are already expressed in brain at E4. Analysis of different brain regions from E4 up to E12 showed a clear and gradual increase of TR $\alpha$ mRNA levels in telencephalon, mesencephalon, and rhombencephalon (including cerebellum, pons, and myelencephalon), while the increase was marginal in diencephalon. In contrast, expression of both $\operatorname{TR} \beta 0$ and TR $\beta 2$ clearly increased in diencephalon and rhombencephalon, whereas there was only a small increase in telencephalon and mesencephalon (Figure 2).
Several studies in older embryos have confirmed that $\operatorname{TR} \alpha$ and $\operatorname{TR} \beta$ are expressed in a spatiotemporal divergent pattern and that TR $\alpha$ is the most widely distributed isoform. Northern blot analysis in embryonic tissues from the second week of incubation onwards showed TR $\alpha$ expression in brain, eye, lung, kidney, heart, liver, intestine, muscle, spleen, red blood cells, and yolk sac [21]. The high expression in embryonic red blood cells confirmed earlier findings obtained by ISH [35]. The TR $\beta 0$ signal on Northern blot was restricted to brain, eye, lung, kidney, and yolk sac [21]. ISH on embryonic brain samples showed that both $\operatorname{TR} \alpha$ and $\operatorname{TR} \beta$ were predominantly expressed in cerebellum. However, while TR $\alpha$ was abundantly present in E15 and E19 cerebellum, TR $\beta 0$ expression was still faint at E19 and increased after hatching [36]. The same research group also found that during eye development, there was a shift from a relatively high TR $\beta 2$ expression to a predominance of TR $\beta 0$ towards the last days of embryonic development [21]. Our group again used qRT-PCR to analyse the expression of TR $\beta 2$ in tissues of late-stage embryos and early posthatch chicks. It was found, as in mammals, that TR $\beta 2$ expression was very restricted in peripheral tissues. At E18 this receptor was 
mainly expressed in brain, thyroid gland, pineal gland, pituitary gland, and retina, with a clear predominance in retina $[37,38]$. More detailed analysis in diencephalon, pituitary, and thyroid gland showed a steady increase in expression from E14 up to E20. Then levels stabilised in diencephalon and pituitary, but they continued to increase in thyroid gland [38].

Zebrafish development from fertilisation to hatching only takes 3 days. The embryos are small and in most studies complete embryos have been pooled for RNA extraction and quantification of TR mRNA levels. Northern blot studies showed that TR $\alpha$ A1 mRNA was clearly present at the start of development but those levels rapidly dropped towards the early gastrula stage. This probably reflects the disappearance of maternal transcripts, since TR $\alpha \mathrm{A} 1$ is only present in high amounts in ovary and testis of adult zebrafish [26, 32]. Zygotic expression of TR $\alpha$ Al could be demonstrated after the mid-blastula transition about 3 hours postfertilisation (hpf) using RNase protection and qRT-PCR, but levels remained very low throughout embryonic and larval development [26, 32]. In contrast, after the disappearance of maternal TR $\alpha \mathrm{A} 1-$ 2 and TR $\alpha \mathrm{B}$ mRNA, zygotic expression of these TR isoforms was increased 5- and 28-fold, respectively, in larvae at 4 days post fertilisation (dpf) compared to embryos at $1 \mathrm{dpf}$ [32]. Except for the recent study of Takayama and colleagues [32], the available RT-PCR expression data were all obtained using primers based exclusively on the thraa sequence and also do not allow to distinguish the different TR $\alpha$ A transcripts. Transcription levels for TR $\alpha$ A and TR $\beta$ have been compared during the first 12 cell cycles of the zebrafish zygote ( $0-4 \mathrm{hpf})$ using semiquantitative RT-PCR. The results showed that the level of maternal TR $\alpha \mathrm{A}$ transcripts was higher than the level of TR $\beta 1$ transcripts, which were already degraded by the 2-cell stage. Zygotic expression of TR $\alpha \mathrm{A}$ and TR $\beta 1$ transcripts could already be shown at the 8- to 16-cell stage, well before the mid-blastula transition and the increase in TR $\alpha \mathrm{A}$ appeared to precede the increase in TR $\beta 1$ [27]. The same research group continued their studies at later stages, showing more or less stable expression of TR $\alpha$ at 1 , 2 , and $3 \mathrm{dpf}$, while TR $\beta$, expression increased substantially between the early gastrula stage (5-6 hpf) and $2 \mathrm{dpf}$ [39]. We measured TR $\alpha$ A expression by qRT-PCR at regular intervals during embryonic development, confirming relatively high mRNA levels at $8 \mathrm{hpf}$ followed by low levels up till hatching [7]. For TR $\beta$ we found more or less stable mRNA levels throughout embryonic development, followed by a rapid increase around hatching [25] (Figure 3). Data of an ISH study for a wide range of nuclear receptors showed no or only baseline signal for TR $\alpha$ in zebrafish embryos, while TR $\beta$ was expressed from approximately $30 \mathrm{hpf}$ onwards in the retina and from approximately $40 \mathrm{hpf}$ onwards also in the mid-and hindbrain $[10,40]$.

\section{TR-Mediated Actions of TH during Embryonic Development}

Thyroid hormones play a major role in the development and maturation of most chicken organs, as is the case in all vertebrates. In addition THs are important in chicken

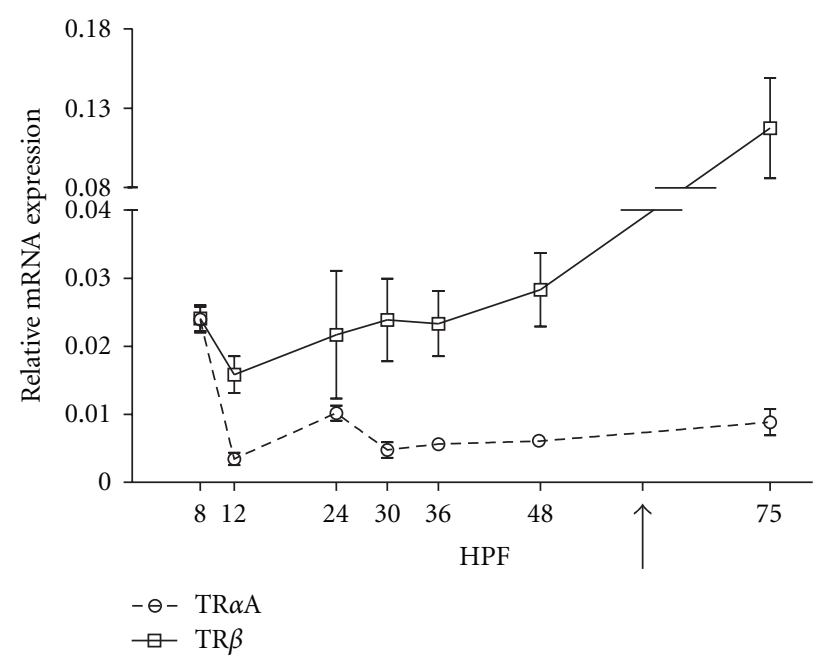

FIgURE 3: Expression of TR $\alpha \mathrm{A}$ and $\mathrm{TR} \beta$ in whole zebrafish embryos during the first three days post fertilisation. Specific mRNA levels were measured by qRT-PCR and normalised against the housekeeping gene Elongation factor $1 \alpha$. Values represent the mean \pm SEM for 3 independent samples (pools of 50-100 embryos) per stage. The arrow indicates the average time of hatching. HPF: hours post fertilisation. Data were taken from [7, 25].

for yolk sac retraction and hatching [41]. While it is clear that nuclear TR-mediated gene transcription is extremely important in the control of these developmental processes, little is known about the specific role of each of the different TR isoforms. In mammals, studies in transgenic mice have contributed substantially to our understanding of the role of each hormone-binding TR variant, leading to the conclusion that all of them seem to have both unique and redundant functions [42-44]. Given the high similarity of chicken TR $\alpha$, $\operatorname{TR} \beta 0$, and $\operatorname{TR} \beta 2$ with mammalian TR $\alpha 1$, TR $\beta 1$, and $\operatorname{TR} \beta 2$, this is probably also the case in chicken and a number of studies indeed point in that direction.

The relatively high expression of TR $\alpha$ in neurectoderm during the first two days of incubation suggests that this receptor plays an important role in the early development of the nervous system [34]. At this moment, it is still unclear whether the main function of TRs at that stage is repression of gene transcription in the unliganded state or whether the low amount of $\mathrm{TH}$ in the embryo is already controlling ligand-dependent stimulation of gene transcription. The latter is possible since $T_{3}$ was shown to be present in the embryo from the first day of incubation and administration of a high dose of $\mathrm{T}_{3}$ disturbed the development of neural tube and brain [34]. We showed that E4 embryos efficiently take up THs from the yolk and injection of surplus hormone at that stage is capable of changing the expression of some TH-responsive genes, including TRs, in the embryonic brain, indicating that ligand-dependent control of gene transcription is possible at these early stages [45, and own unpublished results]. The upregulation of TR protein by $\mathrm{T}_{3}$ found in hypothalamic neurons from E6 embryos kept in culture also points to the early effects of $\mathrm{TH}$-dependent physiological actions of TRs [46]. 
The relatively high expression levels of TR $\beta 2$ at E6 and its progressive decrease later on suggest that this specific TR isoform is important for the early stages of retina development [23]. In ovo treatment of E7 to E12 embryos with $\mathrm{T}_{4}$ accelerates the maturation of the cornea [47], but since all three TR isoforms are expressed in chicken eye by E9 [21, 23], this effect cannot be linked to a specific receptor subtype. Later in development, TR $\beta 2$ seems to be important in feedback regulation of the thyrotropic axis. We found that its expression level in diencephalon and in pituitary closely paralleled the increase in plasma $\mathrm{T}_{4}$ from E14 towards a maximum at E20 and the decrease thereafter. Moreover, a $30 \mathrm{~min}$ in vitro exposure of E18 pituitaries to 10 or $100 \mathrm{nM}$ $\mathrm{T}_{4}$ or $\mathrm{T}_{3}$ reduced TR $\beta 2$ expression by more than half [38]. This would agree with the role of TR $\beta 2$ described in the regulation of TSH and TRH production in mice $[48,49]$ and the negative effect of $\mathrm{T}_{3}$ on the TR $\beta$-mediated TRH transcription found in primary cultures of embryonic chick hypothalamic neurons transiently transfected with $\mathrm{TR} \alpha$ or $\operatorname{TR} \beta[50]$.

Describing the role of the different zebrafish TRs in embryonic development is hampered by the lack of information on their tissue-specific distribution in these early stages since the primers or probes used in many studies, including our own, do not allow to unequivocally identify the distinct transcripts. Moreover, while a multitude of genes have been knocked down using specific morpholino antisense oligomers to study their role in zebrafish embryonic development, the TR genes seem to have escaped notice. It has been suggested that at the beginning of development, in the absence of TH, TR $\alpha$ A1 functions mainly as a transcriptional repressor and that it may repress retinoic acid signalling in blastula- and gastrula-stage embryos [26]. Overexpression of TR $\alpha \mathrm{A} 1$ in early development interfered with the role of retinoic acid in the establishment of the anteroposterior axis in the central nervous system and resulted in severe disruption of the rostral hindbrain [51]. However, although the zebrafish thyroid gland only starts hormone secretion around the time of hatching, zebrafish embryos take up THs from the egg yolk, and hormone-dependent stimulation of gene transcription may occur even in early embryos. We showed that when embryos were reared in medium containing $5 \mathrm{nM} \mathrm{T}_{3}$, hormone levels in the embryos increased dramatically, concomitant with an acceleration of developmental rate and hatching. We also observed an increase in the expression of TR $\alpha$ in $\mathrm{T}_{3}$-treated embryos at $48 \mathrm{hpf}$ compared to controls, while TR $\beta$ expression was not altered [7]. Other investigators found that immersion in $5 \mathrm{nMT}_{3}$ first downregulated TR $\alpha \mathrm{A}$ and TR $\beta 1$ levels, while continued treatment up to $72 \mathrm{hpf}$ resulted in upregulation of expression of both genes [27]. The same group showed that $\mathrm{T}_{3}$ treatment of zebrafish embryos starting at $48 \mathrm{hpf}$ upregulated $\operatorname{TR} \alpha$ and $\operatorname{TR} \beta$ expression, whereas the drug amiodarone that can bind to TRs and antagonise their action strongly inhibited $\operatorname{TR} \alpha$ and $\operatorname{TR} \beta$ expression. This suggests that, as in early chicken embryos, TH can exert a positive autoregulatory feedback control on the transcription of its receptors [39]. This agrees with our studies where we knocked down the type 2 iodothyronine deiodinase, the enzyme converting $T_{4}$ to the receptor-active $T_{3}$. In these embryos, TR $\alpha$ expression was slightly lower at $24 \mathrm{hpf}$ and $31 \mathrm{hpf}$ compared to controls, and TR $\beta$ expression was clearly reduced [52].

\section{Conclusions}

As in other vertebrates, several TR isoforms have been identified in chicken and zebrafish. All of them appear to be fully functional receptors and so far no truncated TRs have been characterised. The different TR variants are expressed throughout embryonic development in spatiotemporal divergent patterns. As in mammals, there seems to be a predominance of $\operatorname{TR} \alpha$ over TR $\beta$ expression at the early stages of embryonic development in both species. Before the embryonic thyroid gland becomes active, chicken and zebrafish embryos have access to THs from a maternal deposit in the yolk, and it has been shown that TH administration to early embryos can stimulate transcription of TH-dependent genes. However, as in mammals, it remains unclear whether the main action of TRs in the first stages of development is the repression of gene transcription in the unliganded form or the stimulation of gene transcription following ligand binding. We also need more data to be able to link the different TR isoforms to specific processes in embryonic development, particularly in zebrafish. In combination with data available from frogs and mammals, this will allow identifying isoform-specific actions that have been conserved throughout vertebrate evolution. Gene knockdown studies and the use of mutant embryos can certainly contribute to solve these questions in the near future. This will even further increase the attractiveness of these externally developing model species for functional genomics studies in relation to the role of THs and their receptors in human development and health.

\section{References}

[1] S. Y. Cheng, J. L. Leonard, and P. J. Davis, "Molecular aspects of thyroid hormone actions," Endocrine Reviews, vol. 31, no. 2, pp. 139-170, 2010.

[2] P. M. Yen, S. Ando, X. Feng, Y. Liu, P. Maruvada, and X. Xia, "Thyroid hormone action at the cellular, genomic and target gene levels," Molecular and Cellular Endocrinology, vol. 246, no. 1-2, pp. 121-127, 2006.

[3] N. Koibuchi, "Animal models to study thyroid hormone action in cerebellum," Cerebellum, vol. 8, no. 2, pp. 89-97, 2009.

[4] Y. B. Shi, "Dual functions of thyroid hormone receptors in vertebrate development: the roles of histone-modifying cofactor complexes," Thyroid, vol. 19, no. 9, pp. 987-999, 2009.

[5] G. M. De Escobar, M. J. Obregón, and F. E. Del Rey, "Role of thyroid hormone during early brain development," European Journal of Endocrinology, Supplement, vol. 151, no. 3, pp. U25U37, 2004.

[6] M. Prati, R. Calvo, and G. M. De Escobar, "L-Thyroxine and 3,5,3'-triiodothyronine concentrations in the chicken egg and in the embryo before and after the onset of thyroid function," Endocrinology, vol. 130, no. 5, pp. 2651-2659, 1992.

[7] C. N. Walpita, S. Van der Geyten, E. Rurangwa, and V. M. Darras, "The effect of 3,5,3'-triiodothyronine supplementation on zebrafish (Danio rerio) embryonic development and 
expression of iodothyronine deiodinases and thyroid hormone receptors," General and Comparative Endocrinology, vol. 152, no. 2-3, pp. 206-214, 2007.

[8] C. D. Stern, "The chick: a great model system becomes even greater," Developmental Cell, vol. 8, no. 1, pp. 9-17, 2005.

[9] P. Haffter and C. Nüsslein-Volhard, "Large scale genetics in a small vertebrate, the zebrafish," International Journal of Developmental Biology, vol. 40, no. 1, pp. 221-227, 1996.

[10] S. Bertrand, B. Thisse, R. Tavares et al., "Unexpected novel relational links uncovered by extensive developmental profiling of nuclear receptor expression," PLoS Genetics, vol. 3, no. 11, pp. 2085-2100, 2007.

[11] S. Bertrand, F. G. Brunet, H. Escriva, G. Parmentier, V. Laudet, and M. Robinson-Rechavi, "Evolutionary genomics of nuclear receptors: from twenty-five ancestral genes to derived endocrine systems," Molecular Biology and Evolution, vol. 21, no. 10, pp. 1923-1937, 2004.

[12] M. Schubert, F. Brunet, M. Paris, S. Bertrand, G. Benoit, and V. Laudet, "Nuclear hormone receptor signaling in amphioxus," Development Genes and Evolution, vol. 218, no. 11-12, pp. 651665,2008

[13] J. H. Oppenheimer, D. Koerner, H. L. Schwartz, and M. I. Surks, "Specific nuclear triiodothyronine binding sites in rat liver and kidney," Journal of Clinical Endocrinology and Metabolism, vol. 35, no. 2, pp. 330-333, 1972.

[14] H. H. Samuels and J. S. Tsai, "Thyroid hormone action. Demonstration of similar receptors in isolated nuclei of rat liver and cultured $\mathrm{GH}_{1}$ cells," Journal of Clinical Investigation, vol. 53, no. 2, pp. 656-659, 1974.

[15] D. Bellabarba and J. G. Lehoux, "Triiodothyronine nuclear receptor in chick embryo: nature and properties of hepatic receptor," Endocrinology, vol. 109, no. 4, pp. 1017-1025, 1981.

[16] D. Bellabarba, S. Bédard, S. Fortier, and J. G. Lehoux, "3,5,3'triiodothyronine nuclear receptor in chick embryo. Properties and ontogeny of brain and lung receptors," Endocrinology, vol. 112, no. 1, pp. 353-359, 1983.

[17] M. A. Haidar and P. K. Sarkar, "Ontogeny, regional distribution and properties of thyroid-hormone receptors in the developing chick brain," Biochemical Journal, vol. 220, no. 2, pp. 547-552, 1984.

[18] J. Sap, A. Muñoz, and K. Damm, "The c-erb-A protein is a high-affinity receptor for thyroid hormone," Nature, vol. 324, no. 6098, pp. 635-640, 1986.

[19] C. Weinberger, C. C. Thompson, and E. S. Ong, "The c-erb-A gene encodes a thyroid hormone receptor," Nature, vol. 324, no. 6098, pp. 641-646, 1986.

[20] B. Vennstrom, "Isolation and characterization of chicken DNA homologous to the two putative oncogenes of avian erythroblastosis virus," Cell, vol. 28, no. 1, pp. 135-143, 1982.

[21] D. Forrest, M. Sjoberg, and B. Vennstrom, "Contrasting developmental and tissue-specific expression of $\alpha$ and $\beta$ thyroid hormone receptor genes," EMBO Journal, vol. 9, no. 5, pp. 1519-1528, 1990.

[22] M. O. Showers, D. S. Darling, G. D. Kieffer, and W. W. Chin, "Isolation and characterization of a cDNA encoding a chicken $\beta$ thyroid hormone receptor," DNA and Cell Biology, vol. 10, no. 3, pp. 211-221, 1991.

[23] M. Sjoberg, B. Vennstrom, and D. Forrest, "Thyroid hormone receptors in chick retinal development: differential expression of mRNAs for $\alpha$ and N-terminal variant $\beta$ receptors," Development, vol. 114, no. 1, pp. 39-47, 1992.

[24] M. Sjöberg and B. Vennstrom, "Ligand-dependent and independent transactivation by thyroid hormone receptor $\beta 2$ is determined by the structure of the hormone response element," Molecular and Cellular Biology, vol. 15, no. 9, pp. 4718-4726, 1995.

[25] C.N. Walpita, The use of zebrafish (Danio rerio) as a model organism to study the role of thyroid hormone in embryonic development of teleost fish, Ph.D. thesis, K.U.Leuven, 2008.

[26] J. J. Essner, J. J. Breuer, R. D. Essner, S. C. Fahrenkrug, and P. B. Hackett, "The zebrafish thyroid hormone receptor $\alpha 1$ is expressed during early embryogenesis and can function in transcriptional repression," Differentiation, vol. 62, no. 3, pp. 107-117, 1997.

[27] Y. W. Liu, L. J. Lo, and W. K. Chan, “Temporal expression and T3 induction of thyroid hormone receptors $\alpha 1$ and $\beta 1$ during early embryonic and larval development in zebrafish, Danio rerio," Molecular and Cellular Endocrinology, vol. 159, no. 1-2, pp. 187-195, 2000.

[28] O. Marchand, R. Safi, H. Escriva, E. Van Rompaey, P. Prunet, and V. Laudet, "Molecular cloning and characterization of thyroid hormone receptors in teleost fish," Journal of Molecular Endocrinology, vol. 26, no. 1, pp. 51-65, 2001.

[29] I. Jones, M. Srinivas, L. Ng, and D. Forrest, "The thyroid hormone receptor $\beta$ gene: structure and functions in the brain and sensory systems," Thyroid, vol. 13, no. 11, pp. 1057-1068, 2003.

[30] E. R. Nelson and H. R. Habibi, "Molecular characterization and sex-related seasonal expression of thyroid receptor subtypes in goldfish," Molecular and Cellular Endocrinology, vol. 253, no. 1-2, pp. 83-95, 2006.

[31] D. M. Power, L. Llewellyn, M. Faustino et al., "Thyroid hormones in growth and development of fish," Comparative Biochemistry and Physiology C, vol. 130, no. 4, pp. 447-459, 2001.

[32] S. Takayama, U. Hostick, M. Haendel, J. Eisen, and B. Darimont, "An F-domain introduced by alternative splicing regulates activity of the zebrafish thyroid hormone receptor $\alpha$," General and Comparative Endocrinology, vol. 155, no. 1, pp. 176-189, 2008.

[33] E. R. Nelson and H. R. Habibi, "Thyroid receptor subtypes: structure and function in fish," General and Comparative Endocrinology, vol. 161, no. 1, pp. 90-96, 2009.

[34] F. Flamant and J. Samarut, "Involvement of thyroid hormone and its $\alpha$ receptor in avian neurulation," Developmental Biology, vol. 197, no. 1, pp. 1-11, 1998.

[35] D. Hentzen, A. Renucci, D. le Guellec et al., "The chicken cerbA proto-oncogene is preferentially expressed in erythrocytic cells during late stages of differentiation," Molecular and Cellular Biology, vol. 7, no. 7, pp. 2416-2424, 1987.

[36] D. Forrest, F. Hallböök, H. Persson, and B. Vennstrom, "Distinct functions for thyroid hormone receptors $\alpha$ and $\beta$ in brain development indicated by differential expression of receptor genes," EMBO Journal, vol. 10, no. 2, pp. 269-275, 1991.

[37] S. V. H. Grommen, B. De Groef, E. R. Kühn, and V. M. Darras, "The use of real-time PCR to study the expression of thyroid hormone receptor $\beta 2$ in the developing chicken," Annals of the New York Academy of Sciences, vol. 1040, pp. 328-331, 2005.

[38] S. V. H. Grommen, L. Arckens, T. Theuwissen, V. M. Darras, and B. De Groef, "Thyroid hormone receptor $\beta 2$ is strongly up-regulated at all levels of the hypothalamopituitary-thyroidal axis during late embryogenesis in chicken," Journal of Endocrinology, vol. 196, no. 3, pp. 519-528, 2008.

[39] Y. W. Liu and W. K. Chan, "Thyroid hormones are important for embryonic to larval transitory phase in zebrafish," Differentiation, vol. 70, no. 1, pp. 36-45, 2002. 
[40] B. Thisse et al., ZFIN database, http://zfin.org/cgi-bin/webdriver?MIval=aa-ZDB_home.apg.

[41] E. Decuypere, E. Dewil, and E. R. Kühn, "The hatching process and the role of hormones," in Avian Incubation, S. G. Tullett, Ed., pp. 239-256, Butterworth \& Heineman, London, UK, 1990.

[42] P. J. O'Shea and G. R. Williams, "Insight into the physiological actions of thyroid hormone receptors from genetically modified mice," Journal of Endocrinology, vol. 175, no. 3, pp. 553570, 2002.

[43] S. Y. Cheng, "Isoform-dependent actions of thyroid hormone nuclear receptors: lessons from knockin mutant mice," Steroids, vol. 70, no. 5-7, pp. 450-454, 2005.

[44] F. Flamant and L. Quignodon, "Use of a new model of transgenic mice to clarify the respective functions of thyroid hormone receptors in vivo," Heart Failure Reviews, vol. 15, no. 2, pp. 117-120, 2010.

[45] S. L. J. Van Herck, S. Geysens, P. Tylzanowski, and V. M. Darras, "Ontogeny of thyroid hormone transport and deiodination in the early chicken brain," submitted to Endocrinology.

[46] F. Lezoualc'h, A. Hassan, H. Abdel-Tawab, J. Puymirat, and B. A. Demeneix, "Precocious auto-induction of thyroid hormone receptors in embryonic chick hypothalamic neurons," Neuroscience Letters, vol. 180, no. 2, pp. 197-202, 1994.

[47] A. H. Conrad, Y. Zhang, A. R. Walker et al., "Thyroxine affects expression of KSPG-related genes, the carbonic anhydrase II gene, and KS sulfation in the embryonic chicken cornea," Investigative Ophthalmology and Visual Science, vol. 47, no. 1, pp. 120-132, 2006.

[48] E.D. Abel, R. S. Ahima, M. E. Boers, J. K. Elmquist, and F. E. Wondisford, "Critical role for thyroid hormone receptor $\beta 2$ in the regulation of paraventricular thyrotropin-releasing hormone neurons," Journal of Clinical Investigation, vol. 107, no. 8, pp. 1017-1023, 2001.

[49] E. D. Abel, E. G. Moura, R. S. Ahima et al., "Dominant inhibition of thyroid hormone action selectively in the pituitary of thyroid hormone-receptor- $\beta$ null mice abolishes the regulation of thyrotropin by thyroid hormone," Molecular Endocrinology, vol. 17, no. 9, pp. 1767-1776, 2003.

[50] F. Lezoualc'h, A. H. S. Hassan, P. Giraud, J. P. Loeffler, S. L. Lee, and B. A. Demeneix, "Assignment of the $\beta$-thyroid hormone receptor to 3,5,3'-triiodothyronine- dependent inhibition of transcription from the thyrotropin-releasing hormone promoter in chick hypothalamic neurons," Molecular Endocrinology, vol. 6, no. 11, pp. 1797-1804, 1992.

[51] J. J. Essner, R. G. Johnson, and P. B. Hackett, "Overexpression of thyroid hormone receptor $\alpha 1$ during zebrafish embryogenesis disrupts hindbrain patterning and implicates retinoic acid receptors in the control of hox gene expression," Differentiation, vol. 65, no. 1, pp. 1-11, 1999.

[52] C. N. Walpita, A. D. Crawford, E. D. R. Janssens, S. Van Der Geyten, and V. M. Darras, "Type 2 lodothyronine deiodinase is essential for thyroid hormone-dependent embryonic development and pigmentation in zebrafish," Endocrinology, vol. 150, no. 1, pp. 530-539, 2009. 


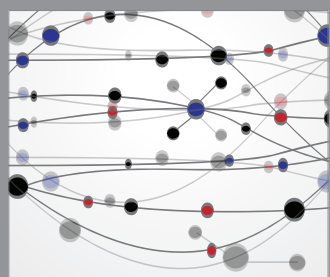

The Scientific World Journal
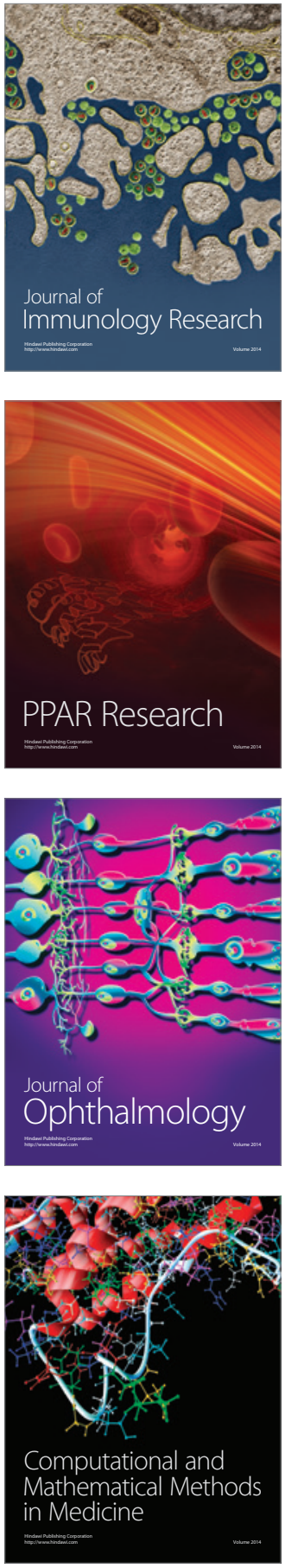

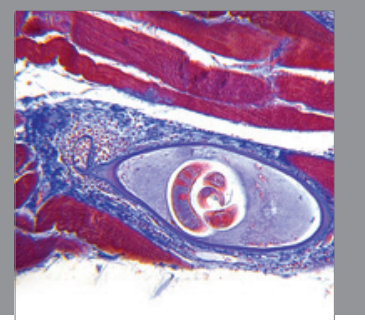

Gastroenterology

Research and Practice
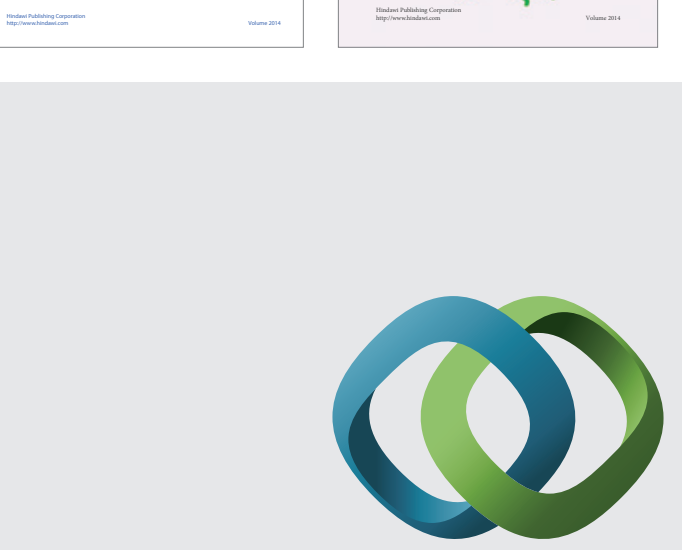

\section{Hindawi}

Submit your manuscripts at

http://www.hindawi.com
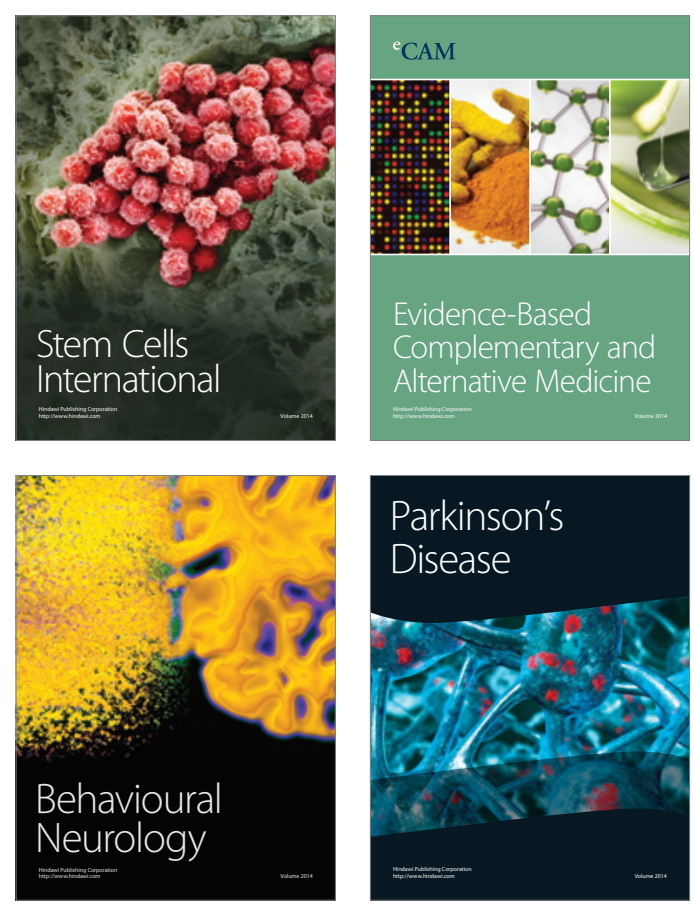

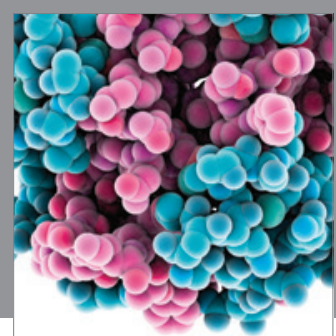

Journal of
Diabetes Research

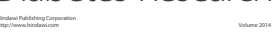

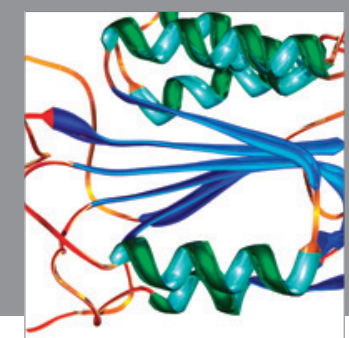

Disease Markers
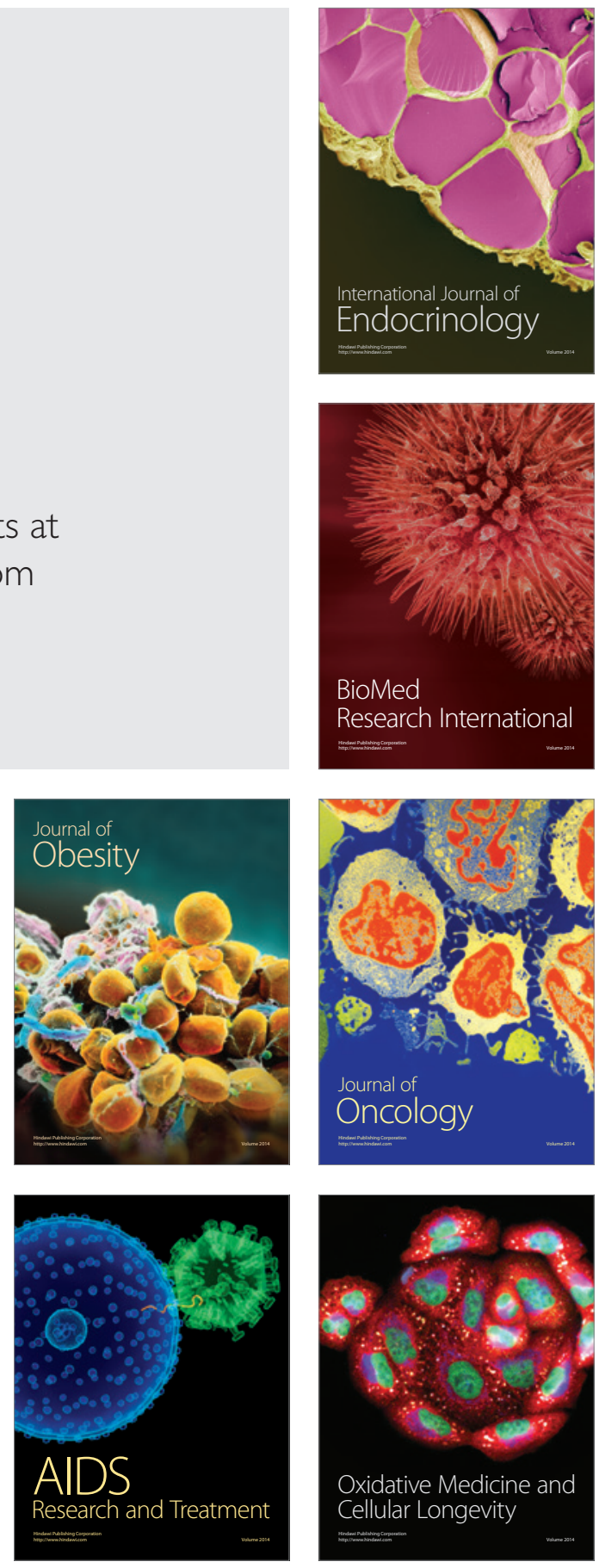